\title{
Sex differences in the burden of type 2 diabetes and cardiovascular risk across the life course
}

\author{
Amy G. Huebschmann ${ }^{1,2} \cdot$ Rachel R. Huxley ${ }^{3,4} \cdot$ Wendy M. Kohrt ${ }^{1,5,6} \cdot$ Philip Zeitler $^{7}$ • Judith G. Regensteiner ${ }^{1,2,8}$. \\ Jane E. B. Reusch ${ }^{1,6,9}$
}

Received: 20 April 2019 / Accepted: 29 May 2019 / Published online: 27 August 2019

(C) Springer-Verlag GmbH Germany, part of Springer Nature 2019

\begin{abstract}
By 2017 estimates, diabetes mellitus affects 425 million people globally; approximately 90-95\% of these have type 2 diabetes. This narrative review highlights two domains of sex differences related to the burden of type 2 diabetes across the life span: sex differences in the prevalence and incidence of type 2 diabetes, and sex differences in the cardiovascular burden conferred by type 2 diabetes. In the presence of type 2 diabetes, the difference in the absolute rates of cardiovascular disease (CVD) between men and women lessens, albeit remaining higher in men. Large-scale observational studies suggest that type 2 diabetes confers $25-$ $50 \%$ greater excess risk of incident CVD in women compared with men. Physiological and behavioural mechanisms that may underpin both the observed sex differences in the prevalence of type 2 diabetes and the associated cardiovascular burden are discussed in this review. Gender differences in social behavioural norms and disparities in provider-level treatment patterns are also highlighted, but not described in detail. We conclude by discussing research gaps in this area that are worthy of further investigation.
\end{abstract}

Keywords Cardiovascular disease $\cdot$ Diabetes mellitus, type $2 \cdot$ Life course development $\cdot$ Lifestyle $\cdot$ Obesity $\cdot$ Review $\cdot$ Sex differences - Type 2 diabetes

\author{
Abbreviations \\ CVD Cardiovascular disease \\ RR Rate ratio
}

Judith G. Regensteiner and Jane E. B. Reusch contributed equally as senior authors of this review.

Electronic supplementary material The online version of this article (https://doi.org/10.1007/s00125-019-4939-5) contains peer-reviewed but unedited supplementary material including a slideset of the figures for download, which is available to authorised users.

Jane E. B. Reusch

jane.reusch@ucdenver.edu

1 Center for Women's Health Research, University of Colorado School of Medicine, MS C263, 12348 E. Montview Boulevard, Aurora, CO 80045, USA

2 Division of General Internal Medicine, University of Colorado School of Medicine, Aurora, CO, USA

3 College of Science, Health and Engineering, La Trobe University, Melbourne, VIC, Australia

4 The George Institute for Global Health, University of New South Wales, Sydney, NSW, Australia
5 Division of Geriatric Medicine, University of Colorado School of Medicine, Aurora, CO, USA

6 Department of Medicine, Rocky Mountain Regional Veterans Affairs Medical Center, Aurora, CO, USA

7 Division of Pediatric Endocrinology, University of Colorado School of Medicine, Aurora, CO, USA

8 Division of Cardiology, University of Colorado School of Medicine (CU-SOM), Aurora, CO, USA

9 Division of Endocrinology, Metabolism and Diabetes, University of Colorado School of Medicine, Aurora, CO, USA 


\section{Introduction}

The presence, type and magnitude of sex and gender differences in type 2 diabetes mellitus and diabetes-mediated risk of cardiovascular disease (CVD) have historically been underappreciated [1]. Epidemiological studies demonstrate clinically relevant sex and gender differences in the rates of type 2 diabetes in youth [2-8] and midlife [9-12]. Sex and gender differences in the impact of type 2 diabetes on CVD outcomes across the life span have also been identified [1, 13-15]. Individuals with type 2 diabetes also exhibit sex and gender differences in the burden of future cancer, dementia and renal disease [16-18]. This narrative review will focus on how age and developmental stages influence two well-recognised areas of sex differences: (1) disparate rates in the prevalence of diabetes, especially during puberty and midlife; and (2) differences in the relative risk of CVD conferred by the presence of type 2 diabetes. The mechanisms that are proposed to influence these sex differences will be summarised, and research gaps that should be addressed to better understand and address the biological underpinnings will be proposed. Given the relevance of biological sex differences in our selected topics, this review is focused on sex rather than gender differences (where gender is defined as comprising social and psychological differences between men and women [19, 20]), although it is often difficult to completely disentangle their effects from each other. In addition, where appropriate, we selectively reference potential gender-related reasons for health disparities among people with type 2 diabetes, including gender differences in healthcare management and socio-environmental factors $[9,21,22]$.

\section{Sex differences in prevalence of type 2 diabetes across the lifespan}

Looking only at the international rates of type 2 diabetes, as standardised across all age groups, the majority of data from populations of Western European or Asian descent suggest a slightly higher prevalence of type 2 diabetes among men than women [23-26]; globally, based upon the IDF 2018 atlas, an estimated 221 million men and 204 million women are estimated to have had type 2 diabetes in 2017 [27]. In terms of time trends, global age-standardised diabetes prevalence $(\%$ [95\% credible interval]) increased from $4.3 \%(2.4,7.0)$ in men in 1980 to $9.0 \%(7.2,11.1)$ in 2014 , and from $5.0 \%(2.9,7.9)$ in women in 1980 to $7.9 \%(6.4,9.7)$ in 2014 [28]. A higher prevalence of type 2 diabetes among men than women may be region specific. For example, in the UK Biobank study, male predominance was reported across three ethnic groups (men vs women): white, $6.0 \%$ vs $3.6 \%(p<0.0001)$; South Asian, $21.0 \%$ vs $13.8 \%(p<0.0001)$; black, $13.3 \%$ vs. $9.7 \%$ $(p<0.0001)$. There was also a non-significant numerical trend in people of Chinese descent [29]. In another Chinese population, the age-standardised prevalence of type 2 diabetes was $16.1 \%$ in men compared with $14.9 \%$ in women $(p<0.0001$ for sex difference) [25], whereas in a US population, there was no sex difference in type 2 diabetes prevalence (men, $12.3 \%$ [95\% CI $11.3 \%, 13.4 \%$ ]; women, $10.8 \%$ [95\% CI 9.8\%, $11.9 \%$ ]) [30]. In addition, no sex differences were observed in the odds of developing diabetes in a meta-analysis of data from sub-Saharan Africa (OR 1.01 [95\% CI 0.91, 1.11]) [31].

There are also some interesting variations in sex differences in type 2 diabetes incidence that fluctuate across the life span, with females having significantly higher rates of type 2 diabetes in youth [2-8], whereas males have a significantly higher prevalence of type 2 diabetes in midlife [9-12], and the rates are fairly similar between the sexes in later life [11, 12]. The next section will summarise the epidemiological differences in type 2 diabetes prevalence across the lifespan, as well as sex differences in the biological predictors of type 2 diabetes, and key research gaps.

\section{Epidemiological differences in type 2 diabetes prevalence across the life span and potential mediators, by life stage}

\section{Sex differences in prevalence of youth-onset type 2 diabetes}

In youth, $<18$ years of age, type 2 diabetes remains generally rare, but its incidence has risen dramatically due to concomitant increases in obesity and suboptimal diet and physical activity behaviours $[2,4,5,32-35]$. Sex differences in the prevalence of type 2 diabetes in youth have been identified; most [2-8], but not all [36] studies that used population-based sampling have reported that approximately two-thirds of children and adolescents diagnosed with type 2 diabetes are female (electronic supplementary material [ESM] Table 1 outlines the study design, methods and findings for four of these studies, from the USA). Time-trend data suggest this disparity may be worsening, as the British Paediatric Surveillance Unit reported that the incidence rate of type 2 diabetes between 2005 and 2015 increased by $58 \%$ in girls but only by $7 \%$ in boys [37], consistent with data from the National Paediatric Diabetes Audit [38]. In contrast, studies of Asian populations reported a higher prevalence of type 2 diabetes in boys compared with girls, highlighting the need to further evaluate race/ethnicity, lifestyle and the environment as risk factors for type 2 diabetes in youth $[8,39]$. A recent report of the Swedish Heart Registry makes the important observation that cardiovascular mortality is significantly higher for people diagnosed with type 2 diabetes at a younger age ( $<40$ years) as compared with those diagnosed at an older age. As such, the predominance of females in youth-onset type 2 diabetes may have major implications in terms of CVD [40]. 


\section{Mechanism of type 2 diabetes onset in youth}

The development of type 2 diabetes in youth is influenced by multifactorial biological and environmental variables, from conception to adolescence. These include genetic risk for type 2 diabetes, epigenetic factors, dietary quality, physical activity, and the surge in sex hormone production and insulin resistance during puberty $[9,32,41,42]$. Emerging research also suggests sexual dimorphism in genetic predictors of adipose fat distribution, inflammatory signalling pathway activation and type 2 diabetes risk [43-48]. Here we will briefly expand on two major risk factors for a type 2 diabetes diagnosis in youth: epigenetic factors and the rise in insulin resistance during puberty.

Epigenetic risk factors The influence of epigenetic risk factors on the development of type 2 diabetes in youth and on cardiometabolic risk across the life span is a rapidly emerging area of research highlighted elsewhere in this special issue by Fernandez-Twinn et al [49] and in other recent reviews [50, 51]. In brief, a few themes emerge in the preclinical data that align with clinical data on sex-specific effects of specific epigenetic factors (reviewed in [50-52]). Paternal undernutrition, overnutrition/high-fat diet and obesity lead to decreased skeletal muscle and beta cell mass, and insulin resistance, with male offspring more affected than female offspring in some studies [53, 54]. Maternal obesity is highly associated with male offspring obesity, and maternal obesity is also linked to a higher risk of diabetes or impaired fasting glucose/impaired glucose tolerance in both sexes [50, 55-57]. In addition, maternal dysglycaemia is more strongly associated with decreased insulin sensitivity in females vs males, and with decreased beta cell mass in both sexes, in reports to date [58-60]. These intriguing data demonstrating the potential for epigenetic risks to be conferred differentially in male and female offspring warrant further evaluation to confirm previous findings and to evaluate potential mechanisms.

Insulin resistance during puberty During puberty, there is an increase in insulin resistance that requires compensatory insulin secretion. The pubertal rise in insulin resistance is accelerated by altered obesity/fat distribution, physical inactivity and high-fat diet, among other factors $[9,61]$. Despite accounting for these individual-level predictors of insulin resistance, sex differences in insulin resistance across the childhood life-phase exist: females have higher rates of insulin resistance than males from early childhood through to mid-puberty, whilst, during late puberty and adulthood, males exhibit greater insulin resistance than females (Fig. 1) [9, 62-66]. This pattern was documented by insulin clamp studies among Caucasian and African-American youths, and persisted with adjustment for measures of adiposity, BMI and objective physical activity levels $[63,64,66]$. In one of the first mechanistic studies in Latino adolescents, both girls and boys increased insulin secretion to compensate for greater insulin resistance in early puberty [67]. By the end of the study, girls had restored insulin sensitivity and normalised insulin secretion, whereas boys had persistently increased insulin resistance and exhibited a decline in beta cell reserve and increased fasting glucose levels [67]. Loss of glucose-stimulated insulin secretion was also observed in the youth type 2 diabetes cohort in the National Institute of Health (NIH) Restoring Insulin Secretion (RISE) study (no sex differences have been reported to date in the 91 participants) [68]. Thus, obesity, insulin resistance and insulin hypersecretion [61] are likely to be key mediators of type 2 diabetes in youth. The distinct role of biological and behavioural factors, however, remains a key gap in the research (Table 1).

\section{Sex differences in type 2 diabetes prevalence in midlife and contributing factors}

In young adults, the rate of diabetes remains fairly low at a population level and epidemiological studies of adults aged $<30$ years do not identify a clear sex difference in the prevalence of type 2 diabetes [9]. In midlife, however, the prevalence of type 2 diabetes tends to be higher in men than in women [9-12]. For example, in a Canadian population-based sample, Lipscombe and Hux observed significant sex differences in both the prevalence and incidence of diabetes among participants aged $\geq 50$ years (men vs women: prevalence, $19.1 \%$ vs $15.4 \%$; incidence, $15.9 / 1000$ vs 12.7/1000; $p<0.001$ for both comparisons), whereas there were no statistically significant sex differences in the prevalence or incidence of type 2 diabetes in people aged 20 49 years [10]. In addition, in a nationally representative Korean sample, there were statistically significant differences in diabetes prevalence between those aged 50-59 years (men: 19.0\% [95\% CI $15.3 \%, 22.8 \%$ ]; women: $8.9 \%$ [95\% CI 5.9\%, 11.9\%]), but there were no longer any sex differences by the seventh decade of life (60-69 year old men: 17.7\% [95\% CI 13.7\%, 21.7\%]; 6069 year old women: $18.5 \%$ [ $95 \%$ CI 14.1\%, $22.8 \%]$ ]), nor were there any significant sex differences in this sample among those aged 30-39 years or 40-49 years [11].

Insulin resistance in men and obesity thresholds in women may, in part, explain the observed sex difference in type 2 diabetes in midlife. As noted earlier, hyperinsulinaemic_euglycaemic insulin clamp data suggest that men are more insulin resistant than women from late puberty into adult life (Fig. 1) [9]. These findings provide a plausible rationale for higher rates of type 2 diabetes among men, but do not explain why the male predominance in type 2 diabetes presents in midlife. Sex differences in the severity of obesity associated with developing type 2 diabetes is another possible factor, with two separate population-based studies demonstrating this; one study showed that women developing type 2 diabetes have a higher BMI than men until the eighth decade of life (Fig. 2c) [41], while the other, in a large cohort of adults in the UK, reported that the age-adjusted average BMI at type 2 diabetes diagnosis was $1.8 \mathrm{~kg} / \mathrm{m}^{2}$ higher in women than in men $(95 \%$ CI $1.7,1.9$; $p<0.01$ ) [69]. 
Potential factors that may be relevant to the equalisation in incidence rates of type 2 diabetes in men and women among older adults could include the changes related to the hormonal transition that occurs during the menopause in women at $\sim 50$ years of age. For example, increased visceral fat deposition among women after menopause may promote increased insulin resistance and elevated incidence of the metabolic syndrome in older women [70, 71].

\section{Sex differences in CVD outcomes for adults with type 2 diabetes across the life span}

Type 2 diabetes is a significant risk factor for CVD for both women and men. Findings from large- scale consortia of cohort studies have shown that the presence of diabetes doubles the risk of having a myocardial infarction or stroke [14, 15, 72]. However, as with other major vascular risk factors, such as blood pressure and BMI, the strength of the association between diabetes and vascular outcomes diminishes with age, partly because of the lower baseline risk for CVD in younger as compared with older adults $[72,73]$. For example, in the largest meta-analysis to date, the rate ratio (RR) of occlusive vascular death was found to be greatest in men and women aged 35-59 years (death RR, 2.60 [95\% CI 2.30, 2.94]), as compared with men and women aged 70-89 years (death RR 2.01 [95\% CI 1.85, 2.19]; $p=0.0001$ for trend across age groups) [72].

Among individuals without diabetes, absolute rates of CVD are higher in men than in women at all ages, apart from at very old ages where the burden of stroke is higher in women than in men irrespective of the presence of diabetes (Table 2) [72]. However, in the presence of type 2 diabetes, the difference in absolute rates between the sexes is substantially diminished (although not fully eliminated), positing some authors to conclude that 'diabetes negates the female advantage' concerning cardiovascular outcomes $[1,14,15,72]$. For example, in three separate large cohorts of young to middle-aged adults, CVD event rates were shown to be similar among women and men with diabetes (women: 17.65, 7.34, and 2.37/1000 person-years in the three

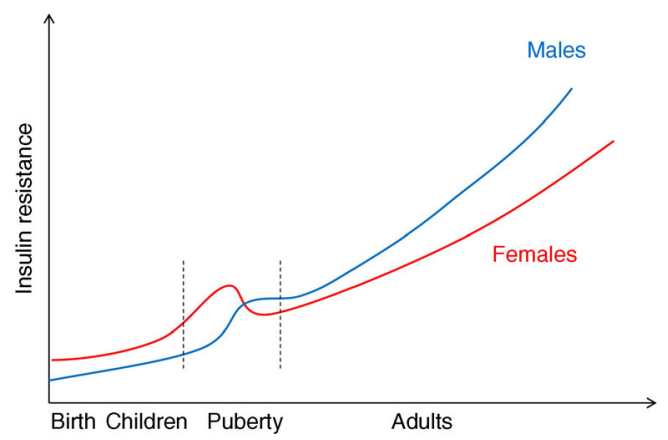

Fig. 1 Sex differences in insulin resistance across the life span. Adapted from [9] with permission from Elsevier. This figure is available as part of a downloadable slideset separate cohorts; men: $12.86,9.71$, and $1.83 / 1000$ person-years, respectively; all logrank $p$ values $>0.05$ [73].

In terms of relative risk for CVD, large meta-analyses of observational data have shown that women with type 2 diabetes have 25-50\% greater excess risk of an incident cardiovascular event compared with similarly affected men $[1,15,72,73]$. For example, recent data from the UK Biobank showed that, in the presence of type 2 diabetes, the excess risk of a cardiovascular event was approximately 50\% higher in women (HR 1.96 [95\% CI 1.60, 2.41]) than in men (HR 1.33 [95\% CI 1.18, 1.51]) [74]. However, this difference has not been observed consistently in some similarly large, contemporary studies $[75,76]$. It is possible that a greater focus on cardiovascular treatment guidelines in recent years has ameliorated the historical treatment disparity between men and women that may have contributed to the observed sex difference in diabetes-related vascular risk [75]. Nevertheless, the observed sex difference is illustrated by the HR conferred by the presence of type 2 diabetes using the validated QRISK3 calculator for 10-year cardiovascular risk [77]. The presence of type 2 diabetes vs no diabetes among women yields a higher HR multiplier (2.91 [95\% CI 2.72, 3.11]) as compared with men with type 2 diabetes vs no diabetes $(2.36$ [95\% CI 2.23, 2.50]) [77]. As the absolute rates of CVD are particularly low in younger age groups, the relative risk of CVD for people with type 2 diabetes vs no type 2 diabetes is higher when type 2 diabetes is diagnosed earlier in life, and is more for women than men [40, 72].

In summary, the presence of type 2 diabetes weakens the cardioprotection that is considered to occur in premenopausal women $[78,79]$. The underlying physiological, behavioural or biological mechanisms that may be responsible for the observed excess risk of vascular disease among women with type 2 diabetes are multifactorial and further research is required (Table 1).

\section{Potential mechanisms for the observed sex difference in the impact of type 2 diabetes on vascular risk}

Numerous studies have speculated on the potential mechanisms (including biological and physiological factors and disparities in disease management) that may underpin the observed excess vascular risk in women compared with men with type 2 diabetes $[1,13]$. This section focuses on the possible biological differences between women and men that may mediate the excess vascular risk in women with type 2 diabetes (Table 1) $[1,14,15,80]$.

Adult women develop type 2 diabetes at a relatively higher BMI than men (Fig. 2). As such, women may experience a prolonged state of insulin resistance and metabolic dysfunction prior to diagnosis with type 2 diabetes $[15,81]$. This theory is supported by the Bogalusa Heart Study's findings that women diagnosed with type 2 diabetes as adults have a greater cumulative exposure to cardiovascular risk factors over their lifetime, starting in youth [82]. For instance, sex 


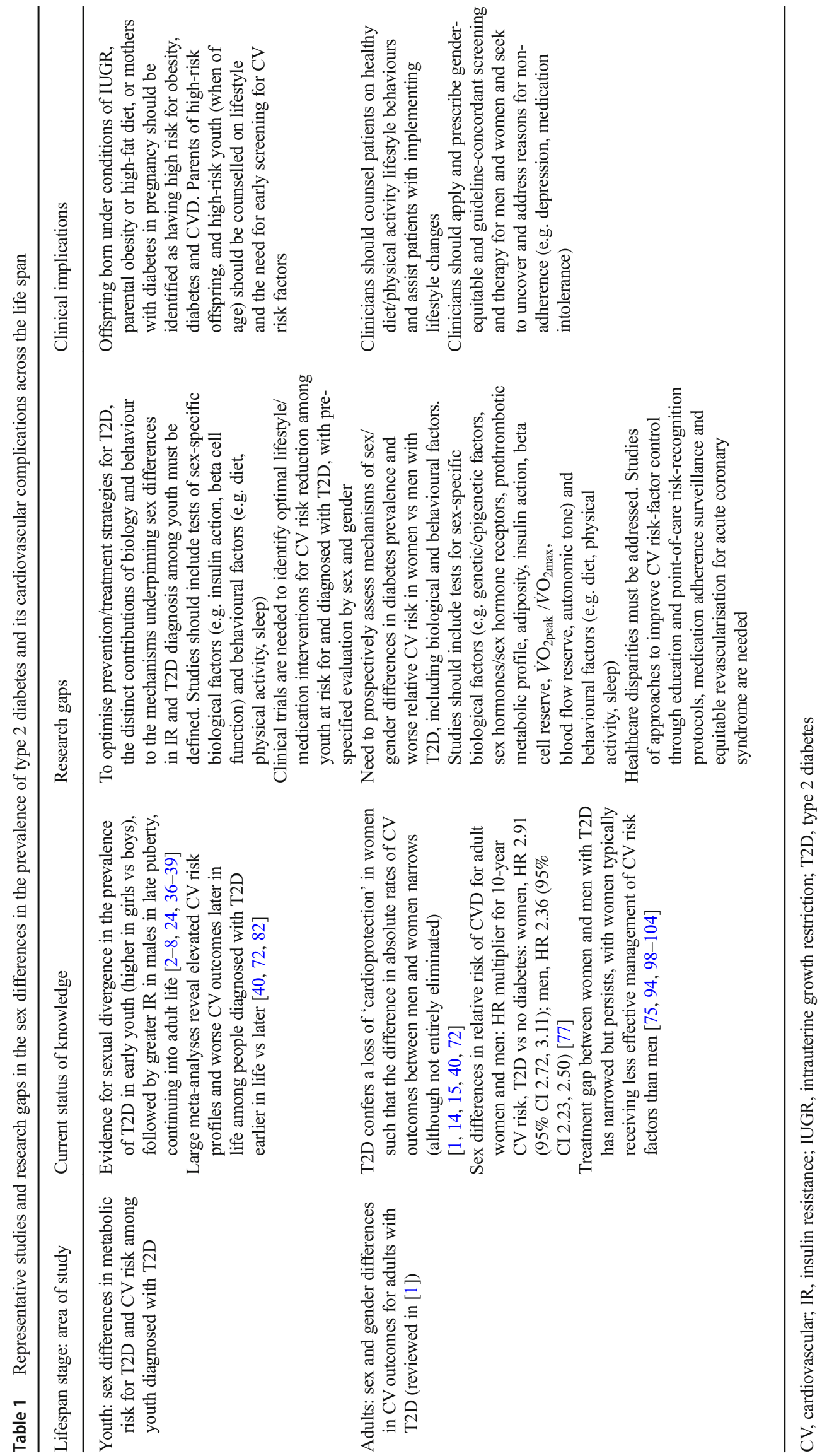



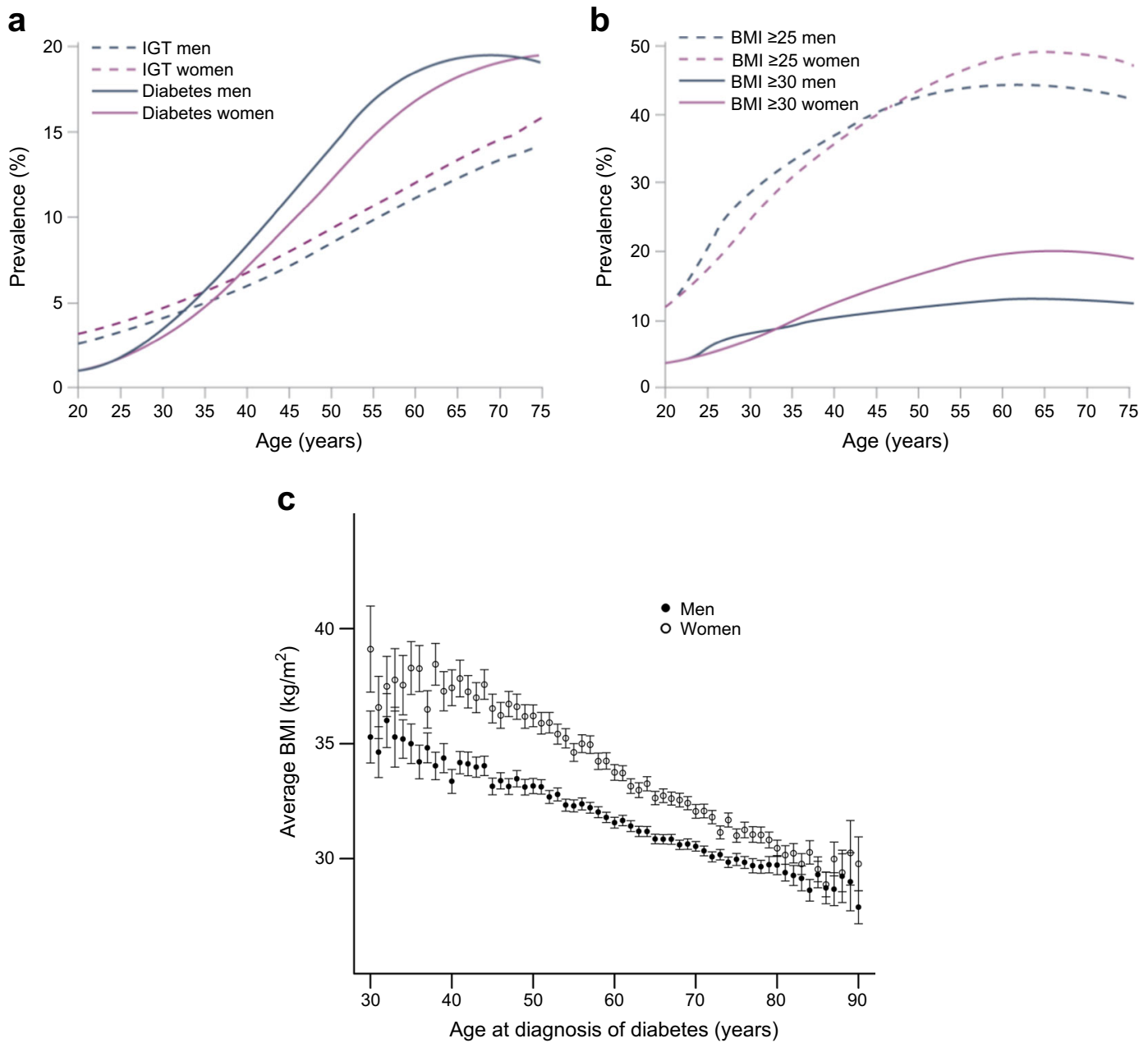

Fig. 2 Obesity levels are higher among women than men at the time of type 2 diabetes diagnosis. (a, b) Sex differences in the prevalence of diabetes/impaired glucose tolerance (IGT) (a) and being overweight $(\mathrm{BMI} \geq 25$ ) or obese (BMI $\geq 30$ ) (b) by age (adapted from [22] by

differences in endothelial dysfunction are a potential biological mediator of the excess vascular risk observed in women with diabetes [83, 84]. The transition from euglycaemia to impaired fasting glucose/impaired glucose tolerance confers more severe endothelial dysfunction in women than men, including changes in markers of endothelial function (E-selectin and soluble intercellular adhesion molecule [sICAM]). In addition, fibrinolysis (plasminogen activator inhibitor-1 [PAI-1]) is more abnormal in premenopausal women with type 2 diabetes than their male counterparts $[83,84]$.

Gender differences in diet and physical activity behaviours warrant consideration for CVD risk and prevention; these have been recently summarised in depth [1]. The notable sex and gender disparities in physical activity behaviour will be briefly reviewed here. Cardiorespiratory fitness, as measured by maximal oxygen capacity $\left(\dot{V} \mathrm{O}_{2 \max }\right) /$ peak oxygen capacity $\left(\dot{V} \mathrm{O}_{2 \text { peak }}\right)$, is a potent predictor of longevity and all-cause mortality and it is lower (worse) in people with diabetes, particularly women [85-87]. In population studies, low levels of physical activity permission of Oxford University Press on behalf of the Endocrine Society). (c) BMI at diabetes diagnosis by age (adapted from [41] by permission from Springer Nature). This figure is available as part of a downloadable slideset

are reported in girls and persist into adulthood. For example, the National Heart, Lung, and Blood Institute Growth and Health Study reported that activity scores for AfricanAmerican girls and Caucasian girls were 27.3 and 30.8 MET-hours per week, respectively, at 9-10 years of age. These scores declined to 0 and 11.0 MET-hours per week by year 10 of the study, when participants were 18 19 years of age $(100 \%$ decline for African-Americans, 64\% decline for Caucasians) [88]. Physical activity levels in women with diabetes are also less than their male counterparts with diabetes, as based on National Health and Nutrition Examination Survey (NHANES) data and baseline data from large interventional studies [89-91]. Sex differences in physical activity among adults with diabetes are exacerbated in populations with lower levels of education, but the gender disparity persists at all levels of education [91]. Considering the significant relationship between physical inactivity in youth and dysglycaemia, the World Health Organization and others have called for 
Table 2 Adjusted rates of cardiovascular mortality among people with and without diabetes, stratified by age and sex

\begin{tabular}{|c|c|c|c|c|c|c|c|}
\hline & \multicolumn{3}{|l|}{ Diabetes } & \multicolumn{3}{|l|}{ No diabetes } & \multirow[t]{2}{*}{ Rate difference $(95 \% \mathrm{CI})$} \\
\hline & Deaths $(n)$ & Person-years & Adjusted rate $(\%)^{\mathrm{a}}$ & Deaths $(n)$ & Person-years & Adjusted rate $(\%)^{\mathrm{a}}$ & \\
\hline \multicolumn{8}{|c|}{ Aged $35-59$ years } \\
\hline Men & 252 & 151,321 & 0.13 & 4579 & $4,168,660$ & 0.06 & $0.08 \%(0.05,0.10)$ \\
\hline Women & 60 & 72,756 & 0.06 & 496 & $2,878,295$ & 0.01 & $0.05 \%(0.03,0.07)$ \\
\hline \multicolumn{8}{|c|}{ Aged 60-69 years } \\
\hline Men & 390 & 62,605 & 0.52 & 5096 & $1,062,761$ & 0.24 & $0.28 \%(0.22,0.34)$ \\
\hline Women & 136 & 32,547 & 0.28 & 974 & 720,144 & 0.07 & $0.20 \%(0.13,0.27)$ \\
\hline \multicolumn{8}{|c|}{ Aged $70-89$ years } \\
\hline Men & 460 & 30,489 & 2.05 & 4473 & 350,754 & 1.14 & $0.91 \%(0.77,1.05)$ \\
\hline Women & 252 & 13,001 & 1.92 & 2518 & 267,099 & 0.84 & $1.08 \%(0.84,1.32)$ \\
\hline
\end{tabular}

${ }^{\text {a }}$ Absolute rates were estimated using Poisson regression stratified by study and adjusted for age at risk (in 5-year age groups), BMI, systolic and diastolic blood pressure, total cholesterol and smoking status [72]

Table adapted from [72] under the terms of the Creative Commons Attribution 4.0 International License (http://creativecommons.org/licenses/by/4.0/), which permits unrestricted use, distribution, and reproduction in any medium

research to increase physical activity in youth and adults, with specific strategies focused on identifying effective approaches to increase physical activity in youth, including developing habits that will persist into adulthood [92, 93].

\section{Sex-specific effects of pharmacotherapy for the management of diabetes}

A potential biological mediator of sex differences in cardiovascular risk factor management among people with type 2 diabetes is the sex-specific efficacy of medications for type 2 diabetes. Initial work in this area has not generally evaluated sex differences in the effectiveness of medications on cardiovascular outcomes in patients with type 2 diabetes, apart from a few studies of glucose-lowering medications. Zinman et al demonstrated no significant sex differences in the effects of an sodium-glucose cotransporter 2 (SGLT2) inhibitor on cardiovascular outcomes in women as compared with men ( $p=0.32$ and $p=$ 0.20 for the effect modification by sex on the outcomes of cardiovascular death or heart failure hospitalisation, respectively) [94]. Data from other trials to date have identified some sex differences in glycaemic response. For example the MASTERMIND and Treatment Options for Type 2 Diabetes in Adolescents and Youth (TODAY) trial reported differences in glycaemic response that were moderated by sex and obesity levels, such that obese females (youth and adults) with type 2 diabetes experienced a better glycaemic response with thiazolidinediones (TZDs) than either non-obese females or obese males, and nonobese males responded significantly better to sulfonylureas than other comparison subgroups $[95,96]$. In studies of glucagon-like peptide-1 (GLP-1) receptor agonists, sex differences have also been reported in glycaemic treatment outcomes, which were greater among men than women, whilst improvements in weight loss favoured women. To date, CVD outcomes with these drugs have not been reported by sex [97].

Comprehensive CVD risk factor reduction is warranted in all people with type 2 diabetes. However, studies have consistently identified a relative undertreatment of women vs men [75, 94, 98-104]. Specifically, women with type 2 diabetes exhibit worse control of $\mathrm{HbA}_{1 \mathrm{c}}$, blood pressure and lipids than men $[75,104,105]$. The treatment disparity between women and men may narrow at older ages, with some studies reporting similar rates of blood pressure and glycaemic control in older women and men with type 2 diabetes [75, 106]. Of note, some authors have suggested that concerns for prescribing teratogenic medications, such as angiotensin-converting enzyme inhibitors, may play a role in the observed sex difference in blood pressure control, but there are other non-teratogenic, effective anti-hypertensive medications that may be used [107]. Further, reports indicate less aggressive use of revascularisation procedures for women with diabetes and coronary heart disease than their male peers, and lower rates of guideline-based care for acute coronary syndrome $[79,105,108]$. Some of the sex differences in the treatment of acute coronary syndrome may be due to delays in diagnosis and treatment because of more frequent 'atypical' symptoms of angina in women than in men, such as fatigue or nausea, instead of 'typical' symptoms of chest pressure and shortness of breath [109]. However, changes in clinical systems to facilitate the ease of use of decision support tools and the availability of acute coronary syndrome protocols that guide appropriate assessments of both women and men have shown early promise in reducing disparities in CVD treatment $[110,111]$, and the additional study of these types of health system interventions is warranted. 


\section{Summary}

\section{Sex differences in the rates of type 2 diabetes and associated CVD across the lifespan}

Females have higher rates of type 2 diabetes in youth, whilst men have higher prevalence in midlife.

In the absence of diabetes, CVD rates are higher in men than women. Diabetes diminishes this difference, and women with type 2 diabetes have a $25-50 \%$ greater excess risk of cardiovascular events vs men.

\section{Mechanism of type 2 diabetes onset in youth}

Development of type 2 diabetes in youth is influenced by biological and environmental variables, e.g. genetic risk, epigenetics, diet, physical activity, and sex hormone production and insulin resistance during puberty.

Some risk factors have differential effects according to sex and stage of life, e.g. insulin resistance is higher in females from childhood to mid-puberty, whilst it is greater in males during late puberty and adulthood.

\section{Mechanisms for sex differences in the impact of type 2 diabetes on cardiovascular risk}

Potential mechanisms for the sex differences in the impact of type 2 diabetes on cardiovascular risk include biological and physiological factors and disparities in disease management between sexes.

For example, women develop type 2 diabetes at a higher BMI than men, so women may experience more prolonged exposure to cardiovascular risk factors prior to type 2 diabetes diagnosis compared with men. Gender differences in diet and physical activity behaviours may also play a role, with cardiorespiratory fitness and physical activity levels being lower in females with diabetes than males.

\section{Sex-specific effects of pharmacotherapy for the management of diabetes/CVD}

Sex-specific efficacy of medications for type 2 diabetes may exist. The few studies that have investigated this show varying sex-specific outcomes of different agents on glycaemic and cardiovascular outcomes.

In terms of CVD risk, there is a relative undertreatment of women vs men, which may narrow at older ages. Recent changes in clinical systems have shown promise in reducing disparities in CVD treatment.

\section{Suggestions for future research}

Mechanistic research to delineate sex-specific pathogenic drivers of type 2 diabetes in young girls, women and middle-aged men is required, as is research to define genetic, cultural and lifestyle factors contributing to sex differences in global type 2 diabetes prevalence.

Clinical trials/observational studies should report sex-stratified results to allow ascertainment of whether sex differences exist in the effects of interventions for the treatment and prevention of type 2 diabetes.

\section{Summary and identification of key research gaps}

Research has historically lacked a systematic approach to the study of sex differences and, as such, the complex interplay between sex and gender, and biological, environmental and behavioural mediators for type 2 diabetes and CVD development has not been well addressed to date. Answers to important questions about the mechanisms underlying sex differences cannot be extracted from re-analysis of existing data and should be evaluated prospectively. It should be noted that although there are distinct biological and behavioural differences between women and men that are likely to impact on the prevalence of type 2 diabetes and associated risk of CVD, sex and gender differences were not the primary pre-specified outcomes of most studies reported in this review. Rigorous and reproducible evaluation of pre-specified outcomes by sex will not be possible until sex considerations and analysis are included at the study-design phase, rather than as a post hoc consideration. Further research is needed that prospectively focuses on sex differences at all stages of the lifespan, to optimally benefit both women and men.

Studies demonstrate that females are more prone to youthonset type 2 diabetes than males [2-8] and males are more prone to midlife type 2 diabetes than females [9-12]. Further mechanistic research to delineate the sex-specific pathogenic drivers of type 2 diabetes in young girls and women and middle-aged men may inform the development of targeted prevention and treatment strategies for men and women (Table 1). Research is also needed to define genetic, cultural and lifestyle factors contributing to sex differences in type 2 diabetes prevalence, globally. This review and others $[1,13]$ have proposed key research gaps in terms of identifying the distinct contributions of biology and 
behaviour to the mechanisms of sex differences across the life span in both type 2 diabetes prevalence and in the cardiovascular burden of type 2 diabetes (Table 1). We reiterate recent editorial statements $[112,113]$ calling for all clinical trials and large-scale observational studies to report sex-stratified results. Such reporting will begin to allow us to reliably ascertain whether sex differences exist in the effects of interventions targeting modifiable lifestyle risk factors and of pharmacotherapy in individuals with type 2 diabetes, as well as other conditions. Moreover, data on sex-specific outcomes will generate new opportunities to reduce sex and gender disparities in type 2 diabetes outcomes, which is highly important since onset of this increasingly prevalent chronic condition can be prevented or delayed with effective evidence-based interventions.

Acknowledgements The authors wish to acknowledge the editorial input provided by S. Hill-Golden (Department of Endocrinology, Johns Hopkins University, MD, USA) on an early version of the manuscript, and the technical assistance of B. Ellis (Center for Women's Health Research, Aurora, CO, USA) with formatting the figures.

Funding This review received no specific grant from any funding agency in the public, commercial or not-for-profit sectors.

Duality of interest AGH, JEBR and JGR report recently completed grant funding from Merck, for an investigator-initiated trial that is outside the scope of the submitted work. JEBR reports a consulting agreement with Oramed. PZ reports unrelated consulting agreements with the following companies: Merck, Daichii-Sankyo, Eli Lilly, BoehringerIngelheim, Takeda and Tolmar. All other authors (RRH, WMK) declare no competing interests.

Contribution statement The authors accept full responsibility for the content of this paper. All authors contributed to developing the scope and design of this narrative review article. With medical informatics consultation, AGH and JEBR conducted the primary literature review and identified the appropriate articles for inclusion. AGH, JGR and JEBR are the guarantors of this work and, as such, had full access to all the data in the study and take responsibility for the integrity of the data and the accuracy of the data presented. AGH and JEBR wrote the initial draft of the paper, RRH and JGR drafted additional tables and sub-sections of the revised paper in response to reviewer feedback, RRH, WMK, JGR and PZ each critically reviewed and edited the manuscript. All authors had an opportunity to contribute to the conclusions of the review and approved the version to be published.

\section{References}

1. Regensteiner JG, Golden S, Huebschmann AG et al (2015) Sex differences in the cardiovascular consequences of diabetes mellitus: a scientific statement from the American Heart Association. Circulation 132(25):2424-2447. https://doi.org/10. 1161/CIR.0000000000000343

2. Dabelea D, Hanson RL, Bennett PH, Roumain J, Knowler WC, Pettitt DJ (1998) Increasing prevalence of type II diabetes in American Indian children. Diabetologia 41(8):904-910. https:// doi.org/10.1007/s001250051006
3. Moore KR, Harwell TS, McDowall JM, Helgerson SD, Gohdes D (2003) Three-year prevalence and incidence of diabetes among American Indian youth in Montana and Wyoming, 1999 to 2001. J Pediatr 143(3):368-371. https://doi.org/10.1067/S00223476(03)00295-6

4. Mayer-Davis EJ, Lawrence JM, Dabelea D et al (2017) Incidence trends of type 1 and type 2 diabetes among youths, 2002-2012. N Engl J Med 376(15):1419-1429. https://doi.org/10.1056/ NEJMoa1610187

5. Schober E, Holl RW, Grabert M et al (2005) Diabetes mellitus type 2 in childhood and adolescence in Germany and parts of Austria. Eur J Pediatr 164(11):705-707. https://doi.org/10.1007/s00431-005-1709-9

6. Wei JN, Sung FC, Lin CC, Lin RS, Chiang CC, Chuang LM (2003) National surveillance for type 2 diabetes mellitus in Taiwanese children. JAMA 290(10):1345-1350. https://doi.org/ 10.1001/jama.290.10.1345

7. Urakami T, Kubota S, Nitadori Y, Harada K, Owada M, Kitagawa $\mathrm{T}$ (2005) Annual incidence and clinical characteristics of type 2 diabetes in children as detected by urine glucose screening in the Tokyo metropolitan area. Diabetes Care 28(8):1876-1881. https:// doi.org/10.2337/diacare.28.8.1876

8. Fu J, Prasad HC (2014) Changing epidemiology of metabolic syndrome and type 2 diabetes in Chinese youth. Curr Diab Rep 14(1):447. https://doi.org/10.1007/s11892-013-0447-z

9. Sattar N (2013) Gender aspects in type 2 diabetes mellitus and cardiometabolic risk. Best Pract Res Clin Endocrinol Metab 27(4): 501-507. https://doi.org/10.1016/j.beem.2013.05.006

10. Lipscombe LL, Hux JE (2007) Trends in diabetes prevalence, incidence, and mortality in Ontario, Canada 1995-2005: a population-based study. Lancet 369(9563):750-756. https://doi. org/10.1016/S0140-6736(07)60361-4

11. Choi YJ, Kim HC, Kim HM, Park SW, Kim J, Kim DJ (2009) Prevalence and management of diabetes in Korean adults: Korea National Health and Nutrition Examination Surveys 1998-2005. Diabetes Care 32(11):2016-2020. https://doi.org/10.2337/dc082228

12. Li J, Ni J, Wu Y et al (2019) Sex differences in the prevalence, awareness, treatment, and control of diabetes mellitus among adults aged 45 years and older in rural areas of northern China: a cross-sectional, population-based study. Front Endocrinol 10:147. https://doi.org/10.3389/fendo.2019.00147

13. Peters SA, Huxley RR, Sattar N, Woodward M (2015) Sex differences in the excess risk of cardiovascular diseases associated with type 2 diabetes: potential explanations and clinical implications. Curr Cardiovasc Risk Rep 9(7):36. https://doi.org/10.1007/ s12170-015-0462-5

14. Peters SA, Huxley RR, Woodward M (2014) Diabetes as a risk factor for stroke in women compared with men: a systematic review and meta-analysis of 64 cohorts, including 775,385 individuals and 12,539 strokes. Lancet 383(9933):1973-1980. https:// doi.org/10.1016/S0140-6736(14)60040-4

15. Peters SA, Huxley RR, Woodward M (2014) Diabetes as risk factor for incident coronary heart disease in women compared with men: a systematic review and meta-analysis of 64 cohorts including 858,507 individuals and 28,203 coronary events. Diabetologia 57(8):1542-1551. https://doi.org/10.1007/s00125014-3260-6

16. Chatterjee S, Peters SA, Woodward M et al (2016) Type 2 diabetes as a risk factor for dementia in women compared with men: a pooled analysis of 2.3 million people comprising more than 100 , 000 cases of dementia. Diabetes Care 39(2):300-307. https://doi. org $/ 10.2337 / \mathrm{dc} 15-1588$

17. Ohkuma T, Peters SAE, Woodward M (2018) Sex differences in the association between diabetes and cancer: a systematic review and meta-analysis of 121 cohorts including 20 million individuals 
and one million events. Diabetologia 61(10):2140-2154. https:// doi.org/10.1007/s00125-018-4664-5

18. Shen Y, Cai R, Sun J et al (2017) Diabetes mellitus as a risk factor for incident chronic kidney disease and end-stage renal disease in women compared with men: a systematic review and meta-analysis. Endocrine 55(1):66-76. https://doi.org/10.1007/s12020-016-1014-6

19. Clayton JA, Tannenbaum C (2016) Reporting sex, gender, or both in clinical research? JAMA 316(18):1863-1864. https://doi.org/ 10.1001/jama.2016.16405

20. Miller LR, Marks C, Becker JB et al (2017) Considering sex as a biological variable in preclinical research. FASEB J 31(1):29-34. https://doi.org/10.1096/fj.201600781R

21. Seghieri G, Policardo L, Anichini R et al (2017) The effect of sex and gender on diabetic complications. Curr Diabetes Rev 13(2): 148-160. https://doi.org/10.2174/1573399812666160517115756

22. Kautzky-Willer A, Harreiter J, Pacini G (2016) Sex and gender differences in risk, pathophysiology and complications of type 2 diabetes mellitus. Endocr Rev 37(3):278-316. https://doi.org/10. 1210/er.2015-1137

23. Tracey ML, McHugh SM, Buckley CM, Canavan RJ, Fitzgerald AP, Kearney PM (2016) The prevalence of type 2 diabetes and related complications in a nationally representative sample of adults aged 50 and over in the Republic of Ireland. Diabet Med 33(4):441-445. https://doi.org/10.1111/dme.12845

24. Jia WP, Pang C, Chen L et al (2007) Epidemiological characteristics of diabetes mellitus and impaired glucose regulation in a Chinese adult population: the Shanghai Diabetes Studies, a cross-sectional 3-year follow-up study in Shanghai urban communities. Diabetologia 50(2):286-292. https://doi.org/10.1007/ s00125-006-0503-1

25. Yang W, Lu J, Weng J et al (2010) Prevalence of diabetes among men and women in China. N Engl J Med 362(12):1090-1101. https://doi.org/10.1056/NEJMoa0908292

26. Nordstrom A, Hadrevi J, Olsson T, Franks PW, Nordstrom P (2016) Higher prevalence of type 2 diabetes in men than in women is associated with differences in visceral fat mass. J Clin Endocrinol Metab 101(10):3740-3746. https://doi.org/10.1210/ jc.2016-1915

27. International Diabetes Federation (2017) IDF diabetes atlas: eighth edition 2017. International Diabetes Federation, Brussels, Belgium. Available from https://diabetes.atlas.org/resources/ 2017-atlas.html. Accessed 13 June 2019

28. NCD Risk Factor Collaboration (2016) Worldwide trends in diabetes since 1980: a pooled analysis of 751 population-based studies with 4.4 million participants. Lancet 387(10027):1513-1530. https://doi.org/10.1016/S0140-6736(16)00618-8

29. Ferguson LD, Ntuk UE, Celis-Morales C et al (2018) Men across a range of ethnicities have a higher prevalence of diabetes: findings from a cross-sectional study of 500000 UK Biobank participants. Diabet Med 35(2):270-276. https://doi.org/10.1111/dme. 13551

30. Centers for Disease Control and Prevention (2017) National Diabetes Statistics Report, 2017. Available from www.cdc.gov/ diabetes/pdfs/data/statistics/national-diabetes-statistics-report.pdf. Accessed 16 April 2019

31. Hilawe EH, Yatsuya H, Kawaguchi L, Aoyama A (2013) Differences by sex in the prevalence of diabetes mellitus, impaired fasting glycaemia and impaired glucose tolerance in sub-Saharan Africa: a systematic review and meta-analysis. Bull World Health Organ 91(9):671-682D. https://doi.org/10.2471/BLT.12.113415

32. Pettitt DJ, Talton J, Dabelea D et al (2014) Prevalence of diabetes in U.S. youth in 2009: the SEARCH for diabetes in youth study. Diabetes Care 37(2):402-408. https://doi.org/10.2337/dc13-1838

33. Lee JH, Kim YM, Kwak MJ et al (2015) Incidence trends and associated factors of diabetes mellitus in Korean children and adolescents: a retrospective cohort study in Busan and Gyeongnam.
Ann Pediatr Endocrinol Metab 20(4):206-212. https://doi.org/10. 6065/apem.2015.20.4.206

34. Ortega-Rodriguez E, Levy-Marchal C, Tubiana N, Czernichow P, Polak M (2001) Emergence of type 2 diabetes in an hospital based cohort of children with diabetes mellitus. Diabetes Metab 27(5 Pt 1):574-578

35. Feltbower RG, McKinney PA, Campbell FM, Stephenson CR, Bodansky HJ (2003) Type 2 and other forms of diabetes in 0-30 year olds: a hospital based study in Leeds, UK. Arch Dis Child 88(8):676-679. https://doi.org/10.1136/adc.88.8.676

36. Isasi CR, Parrinello CM, Ayala GX et al (2016) Sex differences in cardiometabolic risk factors among Hispanic/Latino youth. J Pediatr 176:121-127.e1. https://doi.org/10.1016/j.jpeds.2016.05.037

37. Candler TP, Mahmoud O, Lynn RM, Majbar AA, Barrett TG, Shield JPH (2018) Continuing rise of type 2 diabetes incidence in children and young people in the UK. Diabet Med 35(6):737744. https://doi.org/10.1111/dme.13609

38. Royal College of Paediatrics and Child Health (2017) National Paediatric Diabetes Audit Report 2015-2016. Available from www.rcpch.ac.uk/sites/default/files/NPDA_2015-16_audit_ report.pdf .Accessed 13 June 2019

39. Xu ZR, Zhang MY, Ni JW et al (2019) Clinical characteristics and beta-cell function of Chinese children and adolescents with type 2 diabetes from 2009 to 2018. World J Pediatr. https://doi.org/10.1007/s12519-019-00243-5

40. Sattar N, Rawshani A, Franzen S et al (2019) Age at diagnosis of type 2 diabetes mellitus and associations with cardiovascular and mortality risks findings from the Swedish National Diabetes Registry. Circulation 139(19):2228-2237. https://doi.org/10. 1161/CIRCULATIONAHA.118.037885

41. Logue J, Walker JJ, Colhoun HM et al (2011) Do men develop type 2 diabetes at lower body mass indices than women? Diabetologia 54(12):3003-3006. https://doi.org/10.1007/s00125011-2313-3

42. Peters SAE, Woodward M (2018) Sex differences in the burden and complications of diabetes. Curr Diab Rep 18(6):33. https:// doi.org/10.1007/s11892-018-1005-5

43. Winkler TW, Justice AE, Graff M et al (2015) The influence of age and sex on genetic associations with adult body size and shape: a large-scale genome-wide interaction study. PLoS Genet 11(10): e1005378. https://doi.org/10.1371/journal.pgen.1005378

44. Morris AP, Voight BF, Teslovich TM et al (2012) Large-scale association analysis provides insights into the genetic architecture and pathophysiology of type 2 diabetes. Nat Genet 44(9):981990. https://doi.org/10.1038/ng.2383

45. Sung YJ, Perusse L, Sarzynski MA et al (2016) Genome-wide association studies suggest sex-specific loci associated with abdominal and visceral fat. Int J Obes 40(4):662-674. https://doi. org/10.1038/ijo.2015.217

46. Randall JC, Winkler TW, Kutalik Z et al (2013) Sex-stratified genome-wide association studies including 270,000 individuals show sexual dimorphism in genetic loci for anthropometric traits. PLoS Genet 9(6):e1003500. https://doi.org/10.1371/journal.pgen. 1003500

47. Pulit SL, Karaderi T, Lindgren CM (2017) Sexual dimorphisms in genetic loci linked to body fat distribution. Biosci Rep 37(1): BSR20160184. https://doi.org/10.1042/BSR20160184

48. Henstridge DC, Abildgaard J, Lindegaard B, Febbraio MA (2019) Metabolic control and sex: a focus on inflammatory-linked mediators. Br J Pharmacol. https://doi.org/10.1111/bph.14642

49. Fernandez-Twinn DS, Hjort L, Novakovic B, Ozanne SE, Saffery $\mathrm{R}$ (2019) Intrauterine programming of obesity and type 2 diabetes. Diabetologia. https://doi.org/10.1007/s00125-019-4951-9

50. Dearden L, Bouret SG, Ozanne SE (2018) Sex and gender differences in developmental programming of metabolism. Mol Metab 15:8-19. https://doi.org/10.1016/j.molmet.2018.04.007 
51. Novakovic B, Mansell T, Saffery R (2019) Micromanaging human placental function: differential microRNA expression in fetoplacental endothelial cells of gestational diabetes pregnancies. Clin Sci 133(2):315-319. https://doi.org/10.1042/CS20180901

52. Portha B, Grandjean V, Movassat J (2019) Mother or father: who is in the front line? Mechanisms underlying the non-genomic transmission of obesity/diabetes via the maternal or the paternal line. Nutrients 11(2):233. https://doi.org/10.3390/nu11020233

53. Zhang X, Dong Y, Sun G et al (2019) Paternal programming of liver function and lipid profile induced by a paternal preconceptional unhealthy diet: potential association with altered gut microbiome composition. Kidney Blood Press Res 44(1): 133-148. https://doi.org/10.1159/000497487

54. Cropley JE, Eaton SA, Aiken A et al (2016) Male-lineage transmission of an acquired metabolic phenotype induced by grandpaternal obesity. Mol Metab 5(8):699-708. https://doi.org/10. 1016/j.molmet.2016.06.008

55. Andres A, Hull HR, Shankar K, Casey PH, Cleves MA, Badger TM (2015) Longitudinal body composition of children born to mothers with normal weight, overweight, and obesity. Obesity 23(6):1252-1258. https://doi.org/10.1002/oby.21078

56. Eriksson JG, Sandboge S, Salonen MK, Kajantie E, Osmond C (2014) Long-term consequences of maternal overweight in pregnancy on offspring later health: findings from the Helsinki Birth Cohort Study. Ann Med 46(6):434-438. https://doi.org/10.3109/ 07853890.2014 .919728

57. Blotsky ALRE, Dahhou M, Natkhla M, Dasgupta K (2019) Gestational diabetes associated with incident diabetes in childhood and youth: a retrospective cohort study. CMAJ 191(15): E410-E417. https://doi.org/10.1503/cmaj.181001

58. Krishnaveni GV, Veena SR, Hill JC, Kehoe S, Karat SC, Fall CH (2010) Intrauterine exposure to maternal diabetes is associated with higher adiposity and insulin resistance and clustering of cardiovascular risk markers in Indian children. Diabetes Care 33(2): 402-404. https://doi.org/10.2337/dc09-1393

59. Regnault N, Gillman MW, Rifas-Shiman SL, Eggleston E, Oken E (2013) Sex-specific associations of gestational glucose tolerance with childhood body composition. Diabetes Care 36(10):30453053. https://doi.org/10.2337/dc13-0333

60. Chernausek SD, Arslanian S, Caprio S et al (2016) Relationship between parental diabetes and presentation of metabolic and glycemic function in youth with type 2 diabetes: baseline findings from the TODAY trial. Diabetes Care 39(1):110-117. https://doi. org/10.2337/dc15-1557

61. Erion K, Corkey BE (2018) $\beta$-Cell failure or $\beta$-cell abuse? Front Endocrinol 9:532. https://doi.org/10.3389/fendo.2018.00532

62. Travers SH, Jeffers BW, Bloch CA, Hill JO, Eckel RH (1995) Gender and Tanner stage differences in body composition and insulin sensitivity in early pubertal children. J Clin Endocrinol Metab 80(1):172178. https://doi.org/10.1210/jcem.80.1.7829608

63. Moran A, Jacobs DR Jr, Steinberger J et al (1999) Insulin resistance during puberty: results from clamp studies in 357 children. Diabetes 48(10):2039-2044. https://doi.org/10.2337/diabetes.48.10.2039

64. Moran A, Jacobs DR Jr, Steinberger J et al (2008) Changes in insulin resistance and cardiovascular risk during adolescence: establishment of differential risk in males and females. Circulation 117(18):23612368. https://doi.org/10.1161/CIRCULATIONAHA.107.704569

65. Murphy MJ, Metcalf BS, Voss LD et al (2004) Girls at five are intrinsically more insulin resistant than boys: the Programming Hypotheses revisited - the Earlybird Study (EarlyBird 6). Pediatrics 113(1):82-86. https://doi.org/10.1542/peds.113.1.82

66. Jeffery SC, Hosking J, Jeffery AN et al (2018) Insulin resistance is higher in prepubertal girls but switches to become higher in boys at age 16: a cohort study (EarlyBird 57). Pediatr Diabetes 19(2): 223-230. https://doi.org/10.1111/pedi.12571
67. Kelly LA, Lane CJ, Weigensberg MJ, Toledo-Corral CM, Goran MI (2011) Pubertal changes of insulin sensitivity, acute insulin response, and beta-cell function in overweight Latino youth. J Pediatr 158(3): 442-446. https://doi.org/10.1016/j.jpeds.2010.08.046

68. The RISE Consortium (2018) Metabolic contrasts between youth and adults with impaired glucose tolerance or recently diagnosed type 2 diabetes: II. Observations using the oral glucose tolerance test. Diabetes Care 41(8):1707-1716. https://doi.org/10.2337/dc18-0243

69. Paul S, Thomas G, Majeed A, Khunti K, Klein K (2012) Women develop type 2 diabetes at a higher body mass index than men. Diabetologia 55(5):1556-1557. https://doi.org/10.1007/s00125-0122496-2

70. Gurka MJ, Vishnu A, Santen RJ, DeBoer MD (2016) Progression of metabolic syndrome severity during the menopausal transition. J Am Heart Assoc 5(8):e003609. https://doi.org/10.1161/JAHA. 116.003609

71. Janssen I, Powell LH, Crawford S, Lasley B, Sutton-Tyrrell K (2008) Menopause and the metabolic syndrome: the study of women's health across the nation. Arch Intern Med 168(14): 1568-1575. https://doi.org/10.1001/archinte.168.14.1568

72. Prospective Studies Collaboration, Asia Pacific Cohort Studies Collaboration (2018) Sex-specific relevance of diabetes to occlusive vascular and other mortality: a collaborative meta-analysis of individual data from 980793 adults from 68 prospective studies. Lancet Diabetes Endocrinol 6(7):538-546. https://doi.org/10. 1016/S2213-8587(18)30079-2

73. Kalyani RR, Lazo M, Ouyang P et al (2014) Sex differences in diabetes and risk of incident coronary artery disease in healthy young and middle-aged adults. Diabetes Care 37(3):830-838. https://doi.org/10.2337/dc13-1755

74. Millett ERC, Peters SAE, Woodward M (2018) Sex differences in risk factors for myocardial infarction: cohort study of UK Biobank participants. BMJ 363:k4247. https://doi.org/10.1136/bmj.k4247

75. Wright AK, Kontopantelis E, Emsley R et al (2019) Cardiovascular risk and risk factor management in type 2 diabetes: a population-based cohort study assessing sex disparities. Circulation 139(24):2742-2753. https://doi.org/10.1161/ CIRCULATIONAHA.118.039100

76. Shah AD, Langenberg C, Rapsomaniki E et al (2015) Type 2 diabetes and incidence of cardiovascular diseases: a cohort study in 1.9 million people. Lancet Diabetes Endocrinol 3(2):105-113. https://doi.org/10.1016/S2213-8587(14)70219-0

77. Hippisley-Cox J, Coupland C, Brindle P (2017) Development and validation of QRISK3 risk prediction algorithms to estimate future risk of cardiovascular disease: prospective cohort study. BMJ 357: j2099. https://doi.org/10.1136/bmj.j2099

78. Kanaya AM, Grady D, Barrett-Connor E (2002) Explaining the sex difference in coronary heart disease mortality among patients with type 2 diabetes mellitus: a meta-analysis. Arch Intern Med 162(15): 1737-1745. https://doi.org/10.1001/archinte.162.15.1737

79. Wenger NK (2006) Coronary heart disease in women: highlights of the past 2 years-stepping stones, milestones and obstructing boulders. Nat Clin Pract Cardiovasc Med 3(4):194-202. https:// doi.org/10.1038/ncpcardio0516

80. Giustino G, Redfors B, Mehran R et al (2017) Sex differences in the effect of diabetes mellitus on platelet reactivity and coronary thrombosis: from the Assessment of Dual Antiplatelet Therapy with Drug-Eluting Stents (ADAPT-DES) study. Int J Cardiol 246:20-25. https://doi.org/10.1016/j.ijcard.2017.05.091

81. International Diabetes Federation (2013) IDF Diabetes Atlas: sixth edition. Available from www.idf.org/e-library/epidemiologyresearch/diabetes-atlas/19-atlas-6th-edition.html. Accessed 16 June 2019

82. Du T, Fernandez C, Barshop R et al (2019) Sex differences in cardiovascular risk profile from childhood to midlife between individuals who did and did not develop diabetes at follow-up: the 
Bogalusa Heart Study. Diabetes Care 42(4):635-643. https://doi. org/10.2337/dc18-2029

83. Donahue RP, Rejman K, Rafalson LB, Dmochowski J, Stranges S, Trevisan M (2007) Sex differences in endothelial function markers before conversion to pre-diabetes: does the clock start ticking earlier among women? The Western New York Study. Diabetes Care 30(2):354-359. https://doi.org/10.2337/dc06-1772

84. Vanhoutte PM (2009) Endothelial dysfunction: the first step toward coronary arteriosclerosis. CircJ 73(4):595-601. https://doi. org/10.1253/circj.CJ-08-1169

85. Regensteiner JG, Bauer TA, Huebschmann AG et al (2015) Sex differences in the effects of type 2 diabetes on exercise performance. Med Sci Sports Exerc 47(1):58-65. https://doi.org/10. 1249/MSS.0000000000000371

86. Regensteiner JG, Bauer TA, Reusch JE et al (2009) Cardiac dysfunction during exercise in uncomplicated type 2 diabetes. Med Sci Sports Exerc 41(5):977-984. https://doi.org/10.1249/MSS. 0b013e3181942051

87. Naci H, Ioannidis JP (2013) Comparative effectiveness of exercise and drug interventions on mortality outcomes: metaepidemiological study. BMJ 347:f5577. https://doi.org/10.1136/bmj.f5577

88. Kimm SY, Glynn NW, Kriska AM et al (2002) Decline in physical activity in black girls and white girls during adolescence. N Engl J Med 347(10):709-715. https://doi.org/10.1056/NEJMoa003277

89. The Look AHEAD Research Group (2013) Cardiovascular effects of intensive lifestyle intervention in type 2 diabetes. N Engl J Med 369(2):145-154. https://doi.org/10.1056/NEJMoa1212914

90. Sone H, Tanaka S, limuro S et al (2010) Long-term lifestyle intervention lowers the incidence of stroke in Japanese patients with type 2 diabetes: a nationwide multicentre randomised controlled trial (the Japan Diabetes Complications Study). Diabetologia 53(3):419-428. https://doi.org/10.1007/s00125-009-1622-2

91. Scholes S, Bann D (2018) Education-related disparities in reported physical activity during leisure-time, active transportation, and work among US adults: repeated cross-sectional analysis from the National Health and Nutrition Examination Surveys, 2007 to 2016. BMC Public Health 18(1):926. https://doi.org/10.1186/ s12889-018-5857-z

92. Kallio P, Pahkala K, Heinonen OJ et al (2018) Physical inactivity from youth to adulthood and risk of impaired glucose metabolism. Med Sci Sports Exerc 50(6):1192-1198. https://doi.org/10.1249/ MSS.0000000000001555

93. World Health Organization (2016) WHO Global Report on Diabetes. Available from www.who/int/diabetes/global-report/ en/. Accessed 13 June 2019

94. Zinman B, Inzucchi SE, Wanner C et al (2018) Empagliflozin in women with type 2 diabetes and cardiovascular disease - an analysis of EMPA-REG OUTCOME®. Diabetologia. 61(7):15221527. https://doi.org/10.1007/s00125-018-4630-2

95. Dennis JM, Henley WE, Weedon MN et al (2018) Sex and BMI alter the benefits and risks of sulfonylureas and thiazolidinediones in type 2 diabetes: a framework for evaluating stratification using routine clinical and individual trial data. Diabetes Care 41(9): 1844-1853. https://doi.org/10.2337/dc18-0344

96. TODAY Study Group (2012) A clinical trial to maintain glycemic control in youth with type 2 diabetes. N Engl J Med 366(24): 2247-2256. https://doi.org/10.1056/NEJMoa1109333

97. Anichini R, Cosimi S, Di Carlo A et al (2013) Gender difference in response predictors after 1-year exenatide therapy twice daily in type 2 diabetic patients: a real world experience. Diabetes Metab Syndr Obes 6:123-129. https://doi.org/10.2147/DMSO.S42729

98. Kerr A, Exeter D, Hanham G et al (2014) Effect of age, gender, ethnicity, socioeconomic status and region on dispensing of CVD secondary prevention medication in New Zealand: the Atlas of Health Care Variation CVD cohort (VIEW-1). N Z Med J 127(1400):39-69
99. Lauffenburger JC, Robinson JG, Oramasionwu C, Fang G (2014) Racial/ethnic and gender gaps in the use of and adherence to evidence-based preventive therapies among elderly Medicare Part D beneficiaries after acute myocardial infarction. Circulation 129(7):754-763. https://doi.org/10.1161/ CIRCULATIONAHA.113.002658

100. Vimalananda VG, Miller DR, Hofer TP, Holleman RG, Klamerus ML, Kerr EA (2013) Accounting for clinical action reduces estimates of gender disparities in lipid management for diabetic veterans. J Gen Intern Med 28(Suppl 2):S529-S535. https://doi.org/ 10.1007/s11606-013-2340-5

101. Kramer HU, Raum E, Ruter G et al (2012) Gender disparities in diabetes and coronary heart disease medication among patients with type 2 diabetes: results from the DIANA study. Cardiovasc Diabetol 11(1):88. https://doi.org/10.1186/1475-2840-11-88

102. Winston GJ, Barr RG, Carrasquillo O, Bertoni AG, Shea S (2009) Sex and racial/ethnic differences in cardiovascular disease risk factor treatment and control among individuals with diabetes in the Multi-Ethnic Study of Atherosclerosis (MESA). Diabetes Care 32(8):1467-1469. https://doi.org/10.2337/dc09-0260

103. Franzini L, Ardigo D, Cavalot F et al (2013) Women show worse control of type 2 diabetes and cardiovascular disease risk factors than men: results from the MIND.IT Study Group of the Italian Society of Diabetology. Nutr Metab Cardiovasc Dis 23(3):235241. https://doi.org/10.1016/j.numecd.2011.12.003

104. Peters SAE, Muntner P, Woodward M (2019) Sex differences in the prevalence of, and trends in, cardiovascular risk factors, treatment, and control in the United States, 2001 to 2016. Circulation 139(8):10251035. https://doi.org/10.1161/CIRCULATIONAHA.118.035550

105. Bird CE, Fremont AM, Bierman AS et al (2007) Does quality of care for cardiovascular disease and diabetes differ by gender for enrollees in managed care plans? Womens Health Issues 17(3): 131-138. https://doi.org/10.1016/j.whi.2007.03.001

106. Awa WL, Fach E, Krakow D et al (2012) Type 2 diabetes from pediatric to geriatric age: analysis of gender and obesity among 120,183 patients from the German/Austrian DPV database. Eur J Endocrinol 167(2):245-254. https://doi.org/10.1530/EJE-12-0143

107. Lodi E, Carollo A, Martinotti V, Modena MG (2018) Hypertension and pharmacological therapy in women. High Blood Press Cardiovasc Prev 25(2):147-150. https://doi.org/10. 1007/s40292-018-0257-0

108. Vaccarino V, Rathore SS, Wenger NK et al (2005) Sex and racial differences in the management of acute myocardial infarction, 1994 through 2002. N Engl J Med 353(7):671-682. https://doi. org/10.1056/NEJMsa032214

109. Wenger NK (2016) Clinical presentation of CAD and myocardial ischemia in women. J Nucl Cardiol 23(5):976-985. https://doi. org/10.1007/s12350-016-0593-1

110. Wei J, Mehta PK, Grey E et al (2017) Sex-based differences in quality of care and outcomes in a health system using a standardized STEMI protocol. Am Heart J 191:30-36. https://doi.org/10. 1016/j.ahj.2017.06.005

111. Persell SD, Zei C, Cameron KA, Zielinski M, Lloyd-Jones DM (2010) Potential use of 10-year and lifetime coronary risk information for preventive cardiology prescribing decisions: a primary care physician survey. Arch Intern Med 170(5):470-477. https:// doi.org/10.1001/archinternmed.2009.525

112. Schiebinger L, Leopold SS, Miller VM (2016) Editorial policies for sex and gender analysis. Lancet 388(10062):2841-2842. https://doi.org/10.1016/S0140-6736(16)32392-3

113. The Lancet (2011) Taking sex into account in medicine. Lancet 378(9806):1826. https://doi.org/10.1016/S0140-6736(11)61795-9

Publisher's note Springer Nature remains neutral with regard to jurisdictional claims in published maps and institutional affiliations. 